\title{
Box Transport Mechanism
}

\author{
Ulhas Patil ${ }^{1}$, Tejas Kale ${ }^{2}$, Prasad Kulkarni ${ }^{3}$, Parag Lokhande ${ }^{4}$, Mr. Yogesh Vanjari $^{5}$ \\ ${ }^{1,2,3,4}$ UG student, Department of Mechanical Engineering, GF's Godavari College of Engineering, Jalgaon, India, 425001, \\ ${ }^{5}$ Asstt. Professor, GF's Godavari College of Engineering, Jalgaon, India, 425001
}

\begin{abstract}
This project aims for the utilization of kinematic synthesis (type, dimensional and number) to fabricate a working physical model of an eight link transport mechanism. The mechanism to be developed in its simplest form would perform the function of transporting boxes/articles which are being fed onto two rails and are moved ahead one by one. The eight bar mechanism allows moving more than one article as compared to its four bar counterpart. Transport mechanisms generally move material and their application lies in various industries- manufacturing, assembly, packaging etc.

In this project we apply the path generation synthesis and coupler curve synthesis and study to fabricate our model. It is an eight link transporter mechanism. The synthesis would use of Robert's - Chebyschev theorem for cognate linkages and parallel motion generation. The final model will be constructed by modeling in CAD software that will eliminate the errors that might have crept in graphical synthesis.
\end{abstract}

Keywords- Box Moving Mechanism, Conveyer System, Single Slider Crank Mechanism., CAD software, synthesis.

\section{I -INTRODUCTION}

$\mathbf{T}$ here has been a serious demand for intermittent movement of packages in the industries right from the start. Though the continuous movement is more or less important in the same field the sporadic motion has become essential .The objective of our project is to produce a mechanism that delivers this stop and move motion using mechanical linkages.

The advantage of our system over the conveyor system is that the system has a time delay between moving packages and this delay can be used to introduce any alterations in the package or move the package for any other purpose and likewise. While in conveyor system such actions cannot be performed unless programmed module is used to produce intermittent stopping of the belt which basically is costly. The prototype design requires electric motor, shafts and the frame of which the frame and platform on which the packages are moved is fabricated. All the links are being made of bright metal which reduces the weight of the whole system including the head which has a direct contact with the boxes being moved. The system is expected to move as heavy packages as 2 - $3 \mathrm{kgs}$ approximately.

\section{II- AIM}

The aim of this project is to fabricate the box moving mechanism, which can make easier to move boxes from one section to the other while processing in the factories. In a workstation, an assembly line in order to obtain the required production rate and to achieve a minimum amount of idle time. 


\section{International Journal of Innovations in Engineering and Science, www.ijies.net}

\section{III -OBJECTIVE}

Fabricate a Box transport mechanism which can move things from one place to another Understand project planning and execution. Understand the fabrication techniques in a mechanical workshop. Understand the usage of various mechanical machine tools and also measuring tools.

\section{IV- LITERATURE REVIEW}

A linkage is a mechanism formed by connecting two or more levers together. Linkages can be designed to change the direction of a force or make two or more objects move at the same time. Many different fasteners are used to connect linkages together yet allow them to move freely such as pins, end-threaded bolts with nuts, and loosely fitted rivets. There are two general classes of linkages: simple planar linkages and more complex specialized linkages; both are capable of performing tasks such as describing straight lines or curves and executing motions at differing speeds. The names of the linkage mechanisms given here are widely but not universally accepted in all textbooks and references.

Linkages can be classified according to their primary functions:

- Function generation: the relative motion between the links connected to the frame

- Path generation: the path of a tracer point

- Motion generation: the motion of a coupler

Four different simple planar linkages shown in Fig. 1 are identified by function:-

Reverse-motion linkage: Fig. 1(a) can make objects or force move in opposite directions; this can be done by using the input link as a lever. If the fixed pivot is equidistant from the moving pivots, output link movement will equal input link movement, but it will act in the opposite direction. However, if the fixed pivot is not centered, output link movement will not equal input link movement. By selecting the position of the fixed pivot, the linkage can be designed to produce specific mechanical advantages. This linkage can also be rotated through $360^{\circ} .{ }^{[2]}$

Push-pull linkage: Fig. 1(b) can make the objects or force move in the same direction; the output link moves in the same direction as the input link. Technically classed as a four-bar linkage, it can be rotated through $360^{\circ}$ without changing its function. ${ }^{[2]}$

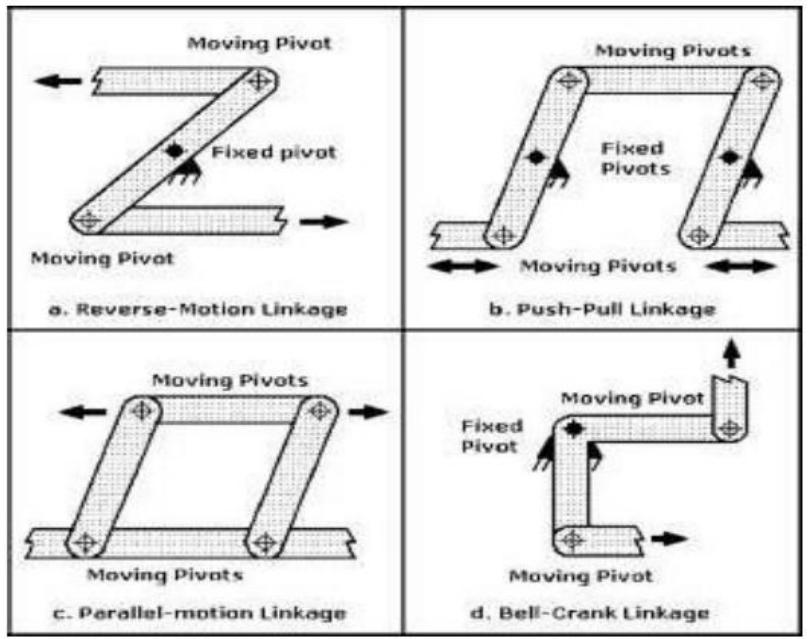

Fig. 1- Functions of four basic planar linkage mechanisms

Parallel-motion linkage: Fig. 1(c), can make objects or forces move in the same direction, but at a set distance apart. The moving and fixed pivots on the opposing links in the parallelogram must be equidistant for this linkage to work correctly. Technically classed as a four-bar linkage, this linkage can also be rotated through $360^{\circ}$ without changing its function. Pantographs that obtain power for electric trains from overhead cables are based on parallel-motion linkage. Drawing pantographs that permit original drawings to be manually copied without tracing or photocopying are also adaptations of this linkage; in its simplest form it can also keep tool trays in a horizontal position when the toolbox covers are opened.

Bell-crank linkage: Fig. 1(d) can change the direction of objects or force by $90^{\circ}$. This linkage rang doorbells before electric clappers were invented. More recently this mechanism has been adapted for bicycle brakes. This was done by pinning two bell cranks bent $90^{\circ}$ in opposite directions together to form tongs. By squeezing the two handlebar levers linked to the input ends of each crank, the output ends will move together. Rubber blocks on the output ends of each crank press against the wheel rim, stopping the bicycle. If the pins which form a fixed pivot are at the midpoints of the cranks, link movement will be equal. However, if those distances vary, mechanical advantage can be gained. ${ }^{[2]}$

\section{Crank-Rocker Mechanism: -}

The four bar linkage is the simplest and often times, the most useful mechanism. As we mentioned before, a mechanism composed of rigid bodies and lower pairs is 
Vol. 6, No. 10, 2021, PP. 149-153

\section{International Journal of Innovations in Engineering and Science, www.ijies.net}

called a linkage. In planar mechanisms, there are only two kinds of lower pairs --- revolute pairs and prismatic pairs. The simplest closed-loop linkage is the four bar linkage which has four members, three moving links, one fixed link and four pin joints. A linkage that has at least one fixed link is a mechanism. ${ }^{[2]}$

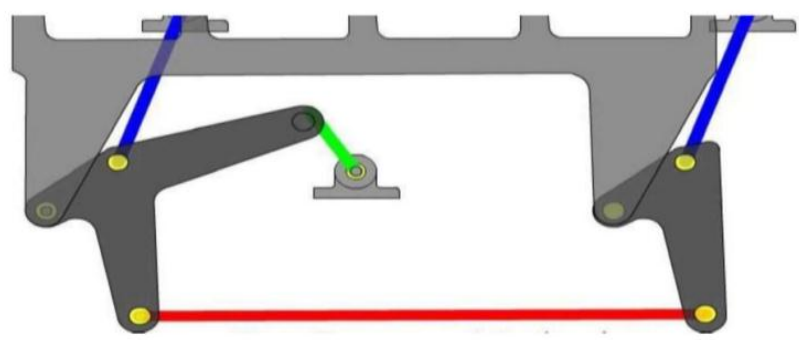

Fig. 2- Crank rocker mechanism

\section{V-WORKING PRINCIPLE}

Crank-Rocker Mechanism: A 4-bar linkage mechanism has a crank that rotates at a constant angular speed. The crank is connected to the coupler which is connected to the rocker. The frame does not move. ${ }^{[3]}$

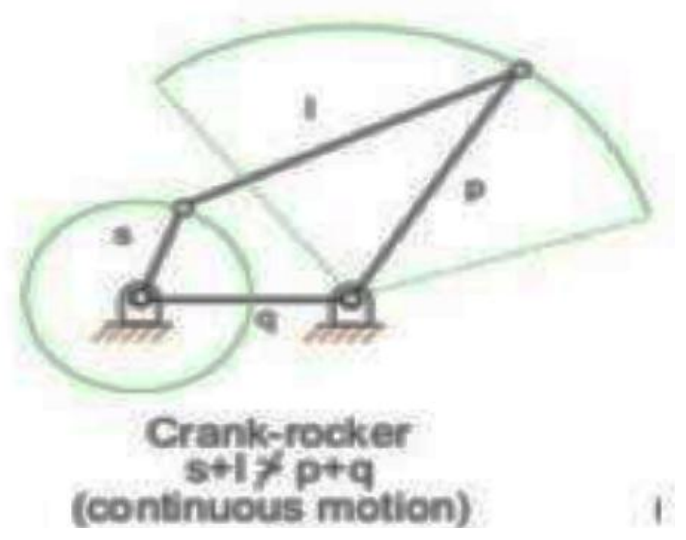

Fig. 3-Crank rocker

Straight-Line Walking Beam Eight-bar Transport Mechanism: -

The walking beam (in blue) pushes articles (in pink) forward, and the material is left stationary in the return stroke of the walking beam until the next cycle. The mechanism is for moving articles with intermittent advancement. The eight-bar mechanism allows moving more than one article, as compared to four bar walking beam. This Working Model file as shown in figure (4) was first developed by Jie (Jeff) Yang.

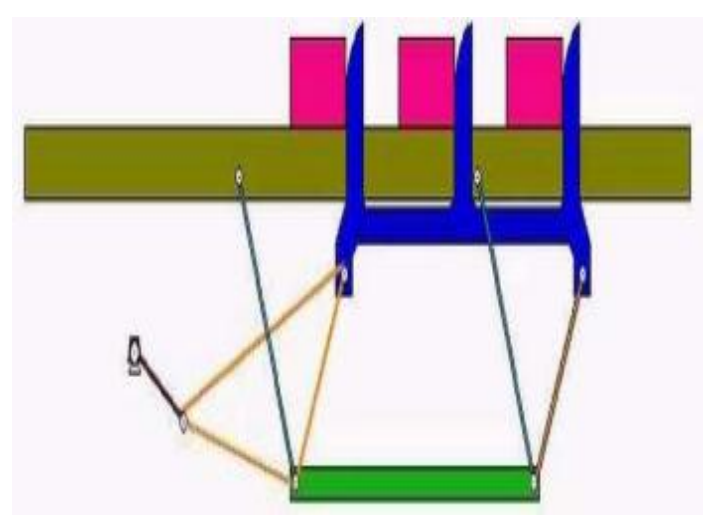

Fig. 4- Straight-Line Walking Beam Eight-bar Transport Mechanism

Before classifying four-bar linkages, we need to introduce some basic nomenclature. In a four-bar linkage, we refer to the line segment between hinges on a given link as a bar

where:

$\mathrm{s}=$ length of shortest bar

$1=$ length of longest bar

$\mathrm{p}, \mathrm{q}=$ lengths of intermediate bar

Grashof's theorem states that a four-bar mechanism has at least one revolving link if

$$
\mathrm{s}+1<=\mathrm{p}+\mathrm{q}(5-1)
$$

And all three mobile links will rock if

$$
\mathrm{s}+\mathrm{l}>\mathrm{p}+\mathrm{q}(5-2)
$$

The inequality 5-1 is Grashof's criterion.

All four-bar mechanisms fall into one of the four categories listed in Table 1.

Table 1- Classification of Four-Bar Mechanisms

\begin{tabular}{|c|c|c|c|c|}
\hline $\begin{array}{c}\text { Sr. } \\
\text { No. }\end{array}$ & Case & $\begin{array}{c}\mathrm{l}+\mathrm{s} \\
\text { varies } \\
\mathrm{p}+\mathrm{q}\end{array}$ & $\begin{array}{c}\text { Shortest } \\
\text { Bar }\end{array}$ & Type \\
\hline 1 & 1 & $<$ & Frame & Double-crank \\
\hline 2 & 2 & $<$ & side & Rocker-crank \\
\hline 3 & 3 & $>$ & Coupler & Double rocker \\
\hline 4 & 4 & $=$ & Any & Change point \\
\hline 5 & 5 & $>$ & Any & Double-rocker \\
\hline
\end{tabular}




\section{International Journal of Innovations in Engineering and Science, www.ijies.net}

VI- DESIGN

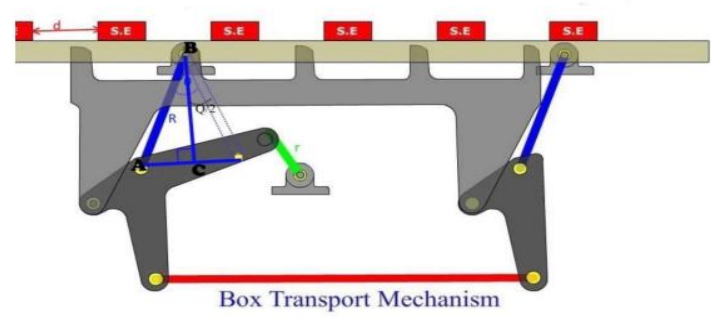

Fig. 5- Box Transport Mechanism

In the given fig value of $d$ is the predetermined value and we have to determine the crank radius $r$ for a given radius value of rocker $\mathrm{R}$.

Let the oscillation of rocker is $\mathrm{Q}$ degree at point $\mathrm{B}$

From the triangle $\mathrm{ABC}$

$$
\begin{gathered}
\mathrm{d}=2 \mathrm{AC} \\
\mathrm{d}=2 \mathrm{R} \sin (\mathrm{Q} / 2) 1 \\
\mathrm{Q} / 2=\sin ^{-1}(\mathrm{~d} / 2 \mathrm{R}) \\
\mathrm{Q}=2 \sin -1(\mathrm{~d} / 2 \mathrm{R})
\end{gathered}
$$

From Crank and Rocker motion

$$
2 \mathrm{r}=\mathrm{R} * \mathrm{Q} * 3.14321 / 180
$$

On putting the value of $\mathrm{Q}$ from equation (1), we get

$$
r=(R * 3.14321 / 180) * \sin ^{-1}(d / 2 R) .
$$

Here, the dimension (radius) of crank for displacement of $215 \mathrm{~mm}$ at the rocker radius of $250 \mathrm{~mm}$.

Given that:

$\mathrm{R}=250 \mathrm{~mm} \& \mathrm{~d}=215 \mathrm{~mm}$

Put the value of $R$ \& $d$ in equation (2),

$r=(250 * 3.14321 / 180) * \operatorname{Sin}-1(215 / 2 * 250)$

$$
\mathrm{r}=111.18 \mathrm{~mm} \quad \text {..Ans. }
$$

Now we will determine the degree of freedom for given mechanism: -

The minimum number of independent variables required to define the position and motion of the system is known as degree of freedom of the system.
OR

Degree of freedom is the number of input required to get constrained output in a chain.

$$
F=3(L-1)-2 J-H
$$

Where

$\mathrm{F}=$ degree of freedom

$\mathrm{L}=$ no of links

$\mathrm{J}=$ no of binary joint

$\mathrm{H}=$ no of higher pair

Hence,

$$
\begin{gathered}
\mathrm{F}=3(8-1)-2 * 10-0 \\
\mathrm{~F}=1
\end{gathered}
$$

\section{VII- APPLICATION AND FUTURE WORK}

Application: -

1. Transferring the boxes from one place to another for the requirement of worker within the industry.

2. Heavy tools easily transport to one work station to another work station.

3. Creating a balance line in the assembly line.

Future scope: - We have tried easy and simple to use prototype design which will revolutionize the concept of box transfer mechanism. As it is easy to use and fabricate small scale industries will be able to utilize this product for the betterment in the plant management. As transporting boxes from the assembly line will get more manageable industries could easily increase their production rate and so their revenue. Further advancements and modifications can be done as per the requirements as well as scale of the use. ${ }^{[2]}$

\section{VIII- CONCLUSION}

In this paper, we learn about how to prepare the Box transporting machine. Other than that we also have been teach by our lecturer how to use the lathe machine. Besides that, our teacher always remains us to stay alert in safety while doing a work before and after finish the practice. Conclusion is, so we just successfully altered this with a box shifting mechanism using the kinematics links and a motor. We used basic mechanical knowledge 
Vol. 6, No. 10, 2021, PP. 149-153

International Journal of Innovations in Engineering and Science, www.ijies.net

and design capabilities to make it possible. Thus this project work will be useful in all industries. For practical application its height, weight are suitable for light duty operations. But with time and with few modifications as the prototype will demand in future, it's efficiency and capabilities could be enhanced.

\section{ACKNOWLEDGEMENT}

We would like to thank, Prof. Y. P. Vanjari for giving guidance, stimulating suggestions and moral support. It had been our privilege to work under his guidance. We would also like to thank Prof. T. A. Koli sir, HOD. We would like to thank our family and friends for their continued support throughout this work.

\section{REFERENCES}

[1] Mohd. Mohtashim Danish, Tushar S. Nitnaware, Piyush Pagar, (2017) "Box Transport Mechanism”.

[2] Siva Krishna Y, Moulali Sk, (2017) "Design And Fabrication Of Box Transport Mechanism”.

[3] Patel Bhautik ,Sharma Saharsh ,Prajapati Ankur, Patel Shweta, Sunil J Pate(2018) "Development Of Box Transfer Mechanism"

[4] P.R.Kothule, M.R.Chavan, S.P.Bhalerao, (2017) "Box Transfer Mechanism, Through Kinematic Link”.

[5] Krupal Tandel, Akbar Khutliwala, Jogesh Harvara, Hirak Mehta4, (2017) "Implementation Of Four Bar Chain Mechanism In Box Transfer Mechanism”. 